\title{
Association between Micronutrient Levels and Chronic Spontaneous Urticaria
}

\author{
Cheng-Han Wu, ${ }^{1,2}$ Efrem Eren, ${ }^{3}$ Michael Roger Ardern-Jones, ${ }^{1}$ and Carina Venter ${ }^{1,4,5}$ \\ ${ }^{1}$ MSc Allergy, Faculty of Medicine, University of Southampton, Southampton, SO16 6YD, UK \\ ${ }^{2}$ Dalin Tzu Chi Hospital, Buddhist Tzu Chi Medical Foundation, Chiayi County, 62247, Taiwan \\ ${ }^{3}$ Southampton General Hospital, Southampton, SO16 6YD, UK \\ ${ }^{4}$ The David Hide Asthma and Allergy Research Center, Isle of Wight, PO30 5TG, UK \\ ${ }^{5}$ University of Portsmouth, Portsmouth, PO1 2UP, UK \\ Correspondence should be addressed to Carina Venter; carina.venter@cchmc.org
}

Received 14 August 2015; Revised 10 October 2015; Accepted 13 October 2015

Academic Editor: Enrico Compalati

Copyright (C) 2015 Cheng-Han Wu et al. This is an open access article distributed under the Creative Commons Attribution License, which permits unrestricted use, distribution, and reproduction in any medium, provided the original work is properly cited.

Previous reports have suggested a possible role for vitamin D in the etiology of chronic spontaneous urticaria (CSU); however, little information is available regarding the role of other micronutrients. We, therefore, analyzed vitamin D, vitamin B12, and ferritin levels in CSU patients $(n=282)$ from a preexisting database at Southampton General Hospital. Data were compared against mean micronutrient levels of the general population of the UK, obtained from the National Diet and Nutrition Survey. Vitamin D levels of CSU patients were found to be higher than those of the general UK population $(P=0.001)$. B12 levels were lower in patients with CSU $(P<0.001)$ than in the general population. Ferritin levels were found to be lower in male CSU patients than in the general male population $(P=0.009)$. This association between low B12 and iron levels and CSU might indicate a causal link, with micronutrient replacement as a potential therapeutic option.

\section{Introduction}

Vitamin D has been suggested to play a role in the aetiology of chronic spontaneous urticaria (CSU) [1-3]. However, the roles of other micronutrients in the development of CSU are unclear. In our clinical immunology practice, we routinely screen for micronutrient deficiencies in patients referred for allergy, immunology, and CSU. We observe that some of our CSU cases exhibit lessening of disease severity upon supplementing with low levels of vitamin D, vitamin B12, or iron, but this often happens alongside medical/dietary interventions that make it difficult to assess the true reason for symptom improvement. Lower vitamin $\mathrm{D}$ levels have previously been reported in CSU patients by Grzanka et al. and Thorp et al. [1, 2] However, the numbers of CSU patients enrolled in both of these studies were small ( 25 and 35 , resp.); therefore, further studies are warranted. Furthermore, Mete et al. studied 33 patients with CSU and reported lower vitamin B12 levels in these patients compared to healthy controls [4]. Recently, Guarneri et al. reported significant improvement in urticaria after iron supplementation in a subgroup of CSU patients with iron deficiency and poor response to antihistamine. A higher prevalence of iron deficiency in CSU patients compared with healthy individuals was also reported in this study [5].

\section{Materials and Methods}

To determine micronutrient levels, vitamin $\mathrm{D}$ (25-hydroxyvitamin D), vitamin B12, ferritin, mean corpuscular volume (MCV), and mean corpuscular haemoglobin concentration (MCHC) levels of 1616 patients with CSU and other common presentations seen in the allergy clinic were extracted from a database at Southampton General Hospital (SGH). Patients between the ages of 19 and 64 years were included (mean age [years] $\pm S D$, vitamin $\mathrm{D}: 41.2 \pm 12.41$ years; vitamin B12: $41.9 \pm 12.40$ years; ferritin: $41.0 \pm 11.72$ years). This was compared with the National Diet and Nutrition Survey (NDNS) conducted between 2008 and 2012 [6]. We also 
TABLE 1: Differences in micronutrient levels between SGH patients and the general UK population, aged 19 to 64 years.

\begin{tabular}{|c|c|c|c|}
\hline & $\begin{array}{c}\text { CSU patients in SGH } \\
(\text { mean } \pm \mathrm{SD})\end{array}$ & $\begin{array}{l}\text { Normal population in NDNS } \\
(\text { mean } \pm \text { SD) }\end{array}$ & $P$ value \\
\hline Vitamin D levels (nmol/L) & $\begin{array}{c}51.4 \pm 27.03 \\
(n=225)\end{array}$ & $\begin{array}{c}45.4 \pm 24.84 \\
(n=1321)\end{array}$ & 0.001 \\
\hline Vitamin D levels (nmol/L), females & $\begin{array}{l}53.1 \pm 27.51 \\
(n=163)\end{array}$ & $\begin{array}{c}47.3 \pm 25.61 \\
(n=770)\end{array}$ & 0.010 \\
\hline Vitamin D levels (nmol/L), males & $\begin{aligned} 46.8 & \pm 25.38 \\
(n & =62)\end{aligned}$ & $\begin{array}{c}43.5 \pm 23.87 \\
\quad(n=551)\end{array}$ & 0.306 \\
\hline Vitamin B12 levels (ng/L) & $\begin{array}{c}284 \pm 108.4 \\
(n=176)\end{array}$ & $\begin{array}{c}359 \pm 131.2 \\
(n=1320)\end{array}$ & $<0.001$ \\
\hline Vitamin B12 levels (ng/L), females & $\begin{array}{c}281 \pm 113.8 \\
(n=133)\end{array}$ & $\begin{array}{c}359 \pm 132.2 \\
(n=768)\end{array}$ & $<0.001$ \\
\hline Vitamin B12 levels (ng/L), males & $\begin{array}{c}295 \pm 89.7 \\
(n=43)\end{array}$ & $\begin{array}{c}359 \pm 130.2 \\
(n=552)\end{array}$ & 0.002 \\
\hline Ferritin levels (ug/L) & $\begin{array}{l}61 \pm 57.0 \\
(n=188)\end{array}$ & $\begin{array}{l}97 \pm 90.2 \\
(n=1329)\end{array}$ & $<0.001$ \\
\hline Ferritin levels (ug/L), females & $\begin{array}{l}48 \pm 44.4 \\
(n=140)\end{array}$ & $\begin{array}{l}56 \pm 53.6 \\
(n=775)\end{array}$ & 0.096 \\
\hline Ferritin levels (ug/L), males & $\begin{array}{c}101 \pm 70.3 \\
(n=48)\end{array}$ & $\begin{aligned} 140 & \pm 100.6 \\
(n & =554)\end{aligned}$ & 0.009 \\
\hline
\end{tabular}

Definition of micronutrient deficiency: vitamin D $<50 \mathrm{nmol} / \mathrm{L}$; vitamin B12 < $130 \mathrm{ng} / \mathrm{L}$; ferritin < $11 \mathrm{ug} / \mathrm{L}$ for females; ferritin $<24$ ug/L for males. NDNS: the National Diet and Nutrition Survey; SGH: Southampton General Hospital.

collected data on sex, date of birth, date of blood test, and the clinical descriptions provided when testing was requested. For vitamin D analysis, we investigated a number of samples collected during different months to determine the potential influence of seasonal variation.

According to the clinical descriptions, only nutrient investigations requested for CSU were included. Patients known to have received nutrient replacement were excluded. To minimize bias resulting from supplementation of nutrients, we excluded data from repetitive tests, unless the nutrient levels remained low or the first result was so high that further supplementation was very unlikely. Testing requested for hereditary angioedema, angioedema related to angiotensin-converting enzyme inhibitors, physical urticaria, acute urticaria/angioedema, urticarial vasculitis, or autoinflammatory syndrome was excluded. Also patients with diagnoses of celiac disease or upper gastrointestinal tract surgery were excluded.

We analysed mean nutrient levels and the proportion of CSU patients with a nutrient deficiency. Data from NDNS were age-matched to our cohort to establish normal population micronutrient levels [6]. Differences between our data and mean nutrient concentrations in the NDNS sample were analysed by using $t$-tests. All statistical analyses were performed using GraphPad Prism software, version 6 (La Jolla, CA, USA). Statistical significance was defined at $P$ values of 0.05 or less.

\section{Results and Discussion}

Of the 1616 patients extracted from the SGH database, 282 patients were identified as having CSU. Most of the CSU patients were female. Vitamin D levels were higher in the
CSU patients than in the general UK population (mean vitamin $\mathrm{D} \pm \mathrm{SD}, 51.4 \pm 27.03$ versus $45.4 \pm 24.84 \mathrm{nmol} / \mathrm{L}$; $P=0.001$; Table 1). However, the majority of people with urticaria (54.6\%) had vitamin D levels below $50 \mathrm{nmol} / \mathrm{L}$. The proportion of samples collected in summer and autumn (between June and November) was 54.1\%.

Compared with the general UK population, CSU patients had significantly lower levels of vitamin B12 but were still within the normal range (mean vitamin B12 \pm SD, 284 \pm 108.4 versus $359 \pm 131.2 \mathrm{ng} / \mathrm{L} ; P<0.001)$. In addition, lower ferritin levels were observed in CSU patients of both sexes (mean ferritin $\pm \mathrm{SD}$, female: $48 \pm 44.4$ versus $56 \pm 53.6 \mathrm{ug} / \mathrm{L}$; male: $101 \pm 70.3$ versus $140 \pm 100.6 \mathrm{ug} / \mathrm{L}$ ), but the difference was not significantly lower in female CSU patients (female: $P=0.096$, versus male: $P=0.009$ ) compared to the general female population. The proportions of patients with low B12 (below $130 \mathrm{ng} / \mathrm{L}$ ) and low ferritin (below $11 \mathrm{ug} / \mathrm{L}$ for females and below $24 \mathrm{ug} / \mathrm{L}$ for males) levels were $4.5 \%$ and $8.5 \%$, respectively. Because full blood count (FBC) testing is recommended by most mainstream urticaria guidelines, we investigated the usefulness of MCV in screening for B12 or iron deficiencies. Out Of 16 patients with low ferritin, only six had MCV values below $80 \mathrm{fL}$ and none had low MCHC. On the other hand, none of the eight patients with low vitamin B12 levels exhibited MCV values above $100 \mathrm{fL}$.

Therefore, in contrast with the results of previous studies $[1,2]$, we observed higher vitamin D levels in our CSU population in comparison with the UK general population. One possible explanation might be the reported effect of latitude in the wide variation of vitamin D levels in the UK population and the southern location of our catchment area [7]. However, we cannot prove it due to the lack of data on vitamin D levels of the general population in Southampton. 
Although the previous cohort reported by Mete et al. ( $n=$ 33) [4] was much smaller than that in our current study, both studies suggest that lower B12 levels are associated with CSU. We also observed an association between iron and CSU, in agreement with a previous study [5]. However, the prevalence of iron deficiency in CSU patients was much lower in our study (16/188 versus $81 / 122)$. Even though the low sensitivity of erythropoietin parameters in the diagnosis of B12 or iron deficiency has been previously reported $[8,9]$, it is worth noting that $\mathrm{FBC}$ alone is not helpful in excluding $\mathrm{B} 12$ or iron deficiencies.

We acknowledge the limitations of this study, including the fact that we did not record dietary or medication history for our cohort; it is possible that variances in diet account for micronutrient differences. For example, an increasing number of patients are taking vitamin $\mathrm{D}$ supplements due to increased public awareness. Nevertheless, we suggest that the lower vitamin B12 and iron levels in CSU patients in our study may indicate that these micronutrients are interesting possible candidates for a role in the initiation or possibly maintenance of CSU. Although the mechanism is still unknown, it could be hypothesized that micronutrients regulate cytokine release following mast cell degranulation by their immunomodulatory properties. Wheatley reported an inverse relationship between vitamin B12 and tumour necrosis factor alpha [10], which is upregulated in CSU patients [11]. Iron-induced decreases in the number of mast cell granules and percentage of mast cell degranulation have also been observed in vitro [12].

\section{Conclusions}

Whether the "low-normal" B12 and ferritin levels seen in most of our CSU cohort reflect either inadequate diets or an etiological role is unclear; however the effect of more general supplementation remains to be established, and a dietary intervention study would be an exciting prospect in this disease area. Further information regarding dietary intake and food avoidance habits of patients with CSU will serve to build on our observations.

\section{Conflict of Interests}

The authors declare that there is no conflict of interests regarding the publication of this paper.

\section{Authors' Contribution}

Cheng-Han $\mathrm{Wu}$ did statistical analysis and preparation of the paper; Efrem Eren did data collection and final paper revision; Michael Ardern-Jones did final paper revision and approval; Carina Venter did initial concept and final paper revision.

\section{Acknowledgment}

The authors are grateful for the support from MSc Allergy Faculty of Medicine, the University of Southampton.

\section{References}

[1] A. Grzanka, E. Machura, B. Mazur et al., "Relationship between vitamin D status and the inflammatory state in patients with chronic spontaneous urticaria," Journal of Inflammation, vol. 11, no. 1, article 2, 2014.

[2] W. A. Thorp, W. Goldner, J. Meza, and J. A. Poole, "Reduced vitamin D levels in adult subjects with chronic urticaria," Journal of Allergy and Clinical Immunology, vol. 126, no. 2, p. 413, 2010

[3] A. Rorie, W. S. Goldner, E. Lyden, and J. A. Poole, "Beneficial role for supplemental vitamin D3 treatment in chronic urticaria: a randomized study," Annals of Allergy, Asthma and Immunology, vol. 112, no. 4, pp. 376-382, 2014.

[4] N. Mete, O. Gulbahar, A. Aydin, A. Z. Sin, A. Kokuludag, and F. Sebik, "Low B12 levels in chronic idiopathic urticaria," Journal of Investigational Allergology and Clinical Immunology, vol. 14, no. 4, pp. 292-299, 2004.

[5] F. Guarneri, C. Guarneri, and S. P. Cannavò, "Oral iron therapy and chronic idiopathic urticaria: sideropenic urticaria?" Dermatologic Therapy, vol. 27, no. 4, pp. 223-226, 2014.

[6] S. Nicholson, G. Pot, C. Bates, A. Prentice, L. Cox, and P. Page, "Blood analytes," in National Diet and Nutrition Survey Results from Years 1, 2, 3 and 4 (Combined) of the Rolling Programme (2008/2009-2011/2012), B. Bates, A. Lennox, A. Prentice et al., Eds., pp. 101-122, Public Health England, 2014.

[7] E. Hyppönen and C. Power, "Hypovitaminosis D in British adults at age $45 \mathrm{y}$ : nationwide cohort study of dietary and lifestyle predictors," American Journal of Clinical Nutrition, vol. 85, no. 3, pp. 860-868, 2007.

[8] C. Ceylan, M. Miskioglu, H. Colak, B. Kiliccioglu, and E. Ozdemir, "Evaluation of reticulocyte parameters in iron deficiency, vitamin $\mathrm{B}_{12}$ deficiency and $\beta$-thalassemia minor patients," International Journal of Laboratory Hematology, vol. 29, no. 5, pp. 327-334, 2007.

[9] G. S. Sultana, S. A. Haque, T. Sultana, and A. N. Ahmed, "Value of red cell distribution width (RDW) and RBC indices in the detection of iron deficiency anemia," Mymensingh Medical Journal, vol. 22, no. 2, pp. 370-376, 2013.

[10] C. Wheatley, "A scarlet pimpernel for the resolution of inflammation? The role of supra-therapeutic doses of cobalamin, in the treatment of systemic inflammatory response syndrome (SIRS), sepsis, severe sepsis, and septic or traumatic shock," Medical Hypotheses, vol. 67, no. 1, pp. 124-142, 2006.

[11] S. Piconi, D. Trabattoni, E. Iemoli et al., "Immune profiles of patients with chronic idiopathic urticaria," International Archives of Allergy and Immunology, vol. 128, no. 1, pp. 59-66, 2002.

[12] L. P. Hale, E. P. Kant, P. K. Greer, and W. M. Foster, "Iron supplementation decreases severity of allergic inflammation in murine lung," PLoS ONE, vol. 7, no. 9, Article ID e45667, 2012. 


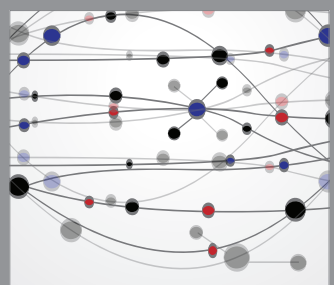

The Scientific World Journal
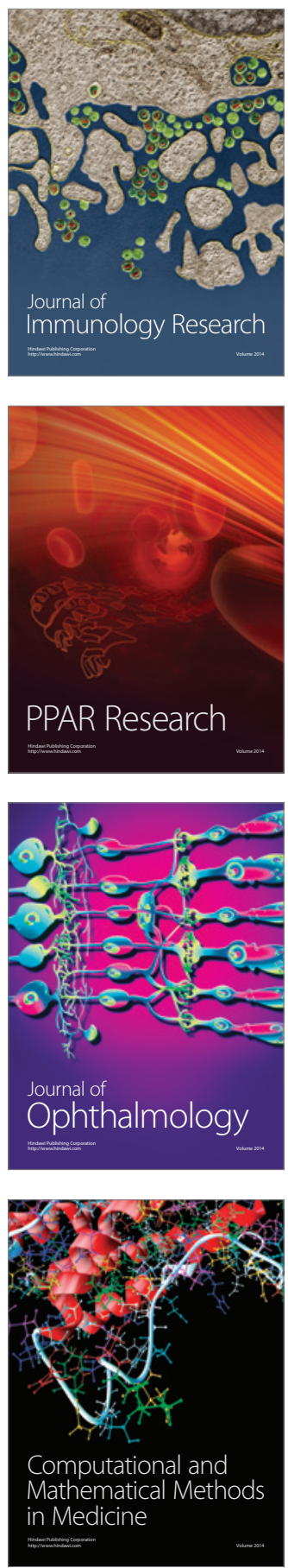

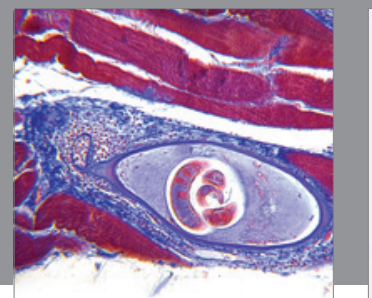

Gastroenterology

Research and Practice
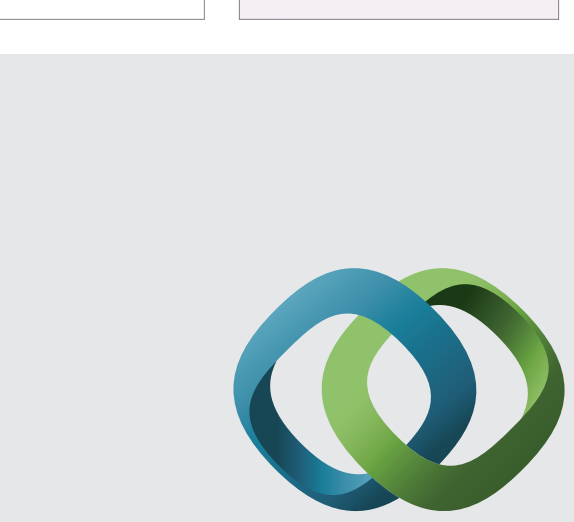

\section{Hindawi}

Submit your manuscripts at

http://www.hindawi.com
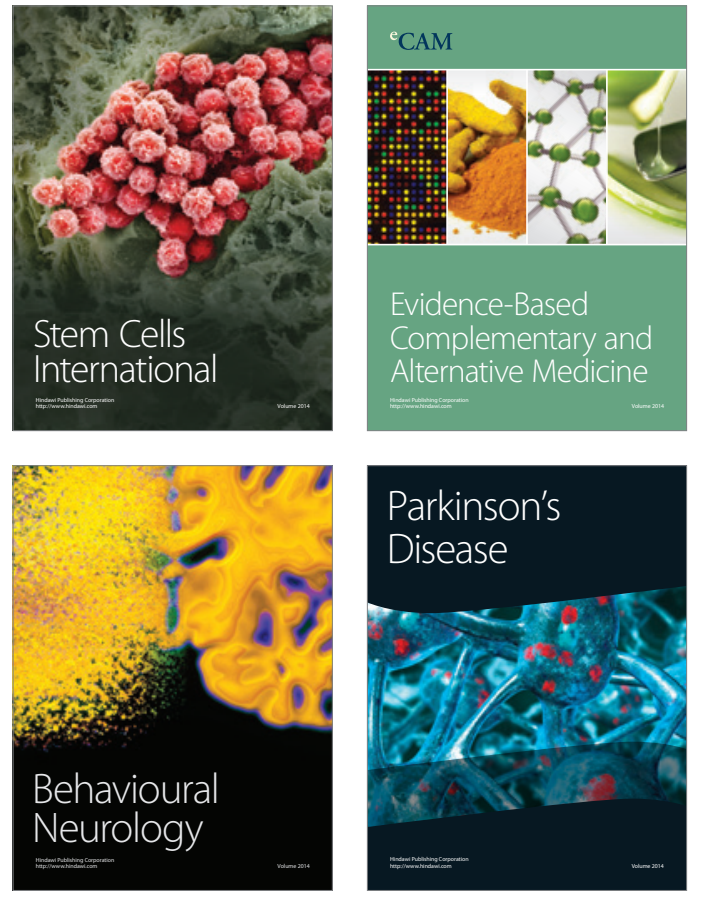
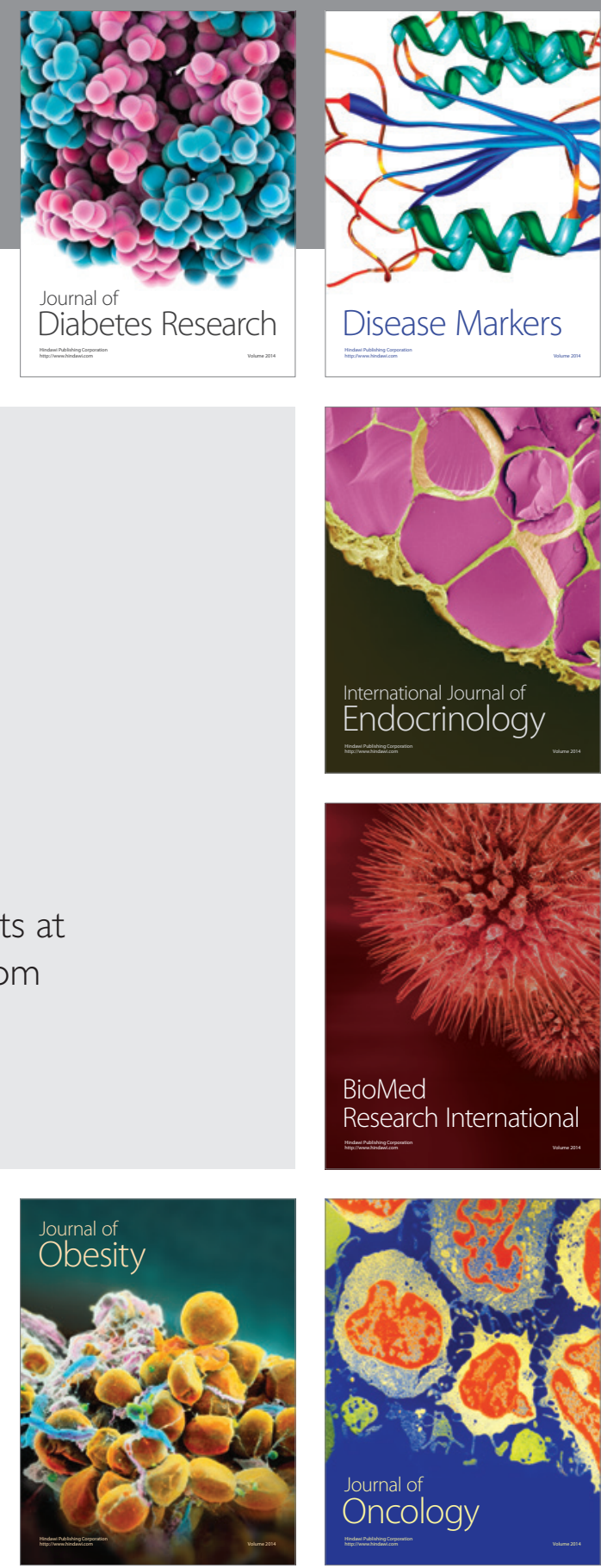

Disease Markers
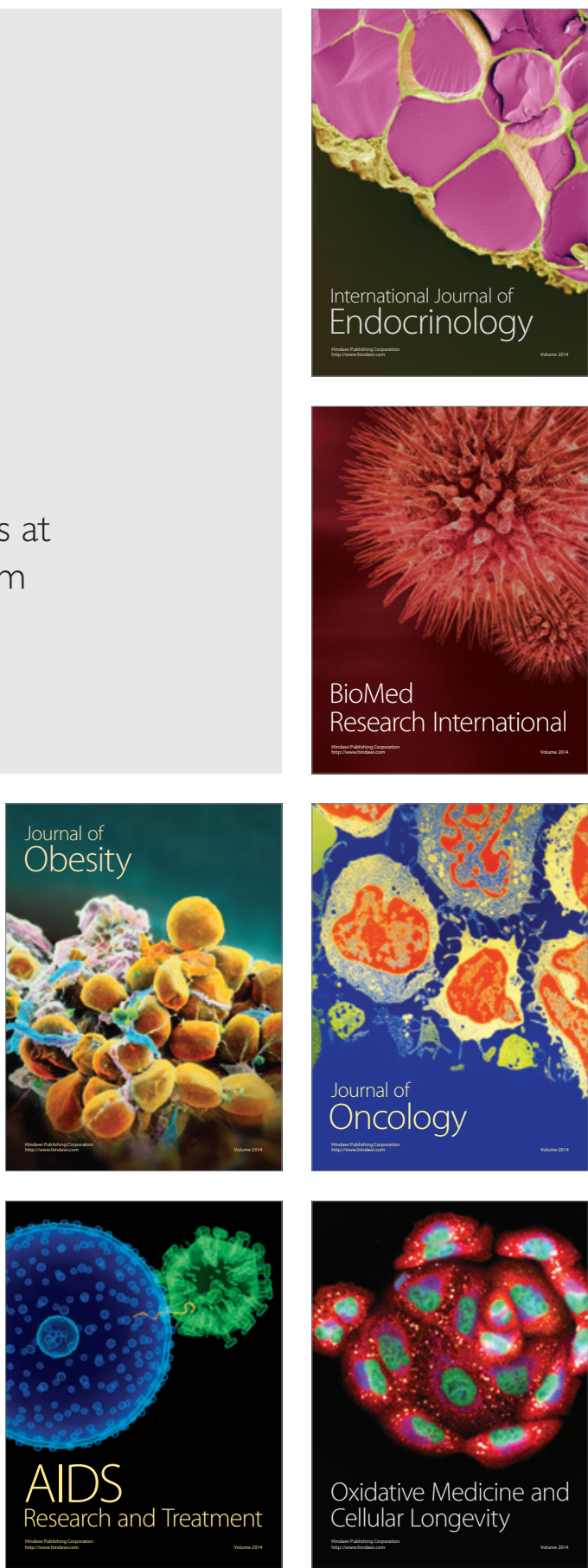